\title{
ANÁLISE ERGONÔMICA DOS POSTOS DE TRABALHO DE OPERADORES DE CAIXA DE SUPERMERCADO
}

\section{ERGONOMICS ANALYSIS IN SUPERMARKET CASH REGISTERS}

\section{Lucimara Ballardin}

Fisioterapeuta e Mestranda em Engenharia de Produção Universidade Federal do Rio Grande do Sul Programa de Pós-graduação em Engenharia de Produção Praça Argentina, ${ }^{\circ} 9$, Porto Alegre

Telefone: (51) 8408-7744 luciballardin@yahoo.com.br

\section{Cristiane Fontoura}

Fisioterapeuta

Universidade Federal de Santa Maria

Departamento de Fisioterapia e Reabilitação

Avenida Roraima, s/n. Santa Maria, RS

Telefone: (51) 84243841 cristiane-fontoura@bol.com.br

\author{
Carmen Silvia Fellippa, Dr. \\ Professora Adjunta \\ Universidade Federal de Santa Maria \\ Departamento de Fisioterapia e Reabilitação \\ Avenida Roraima, s/n. Santa Maria, RS \\ silviafellippa@excite.com
}

\section{Maria Saleti Vogt, MSc.}

Professora Adjunta e Doutoranda na Universidade de Brasília Universidade Federal de Santa Maria

Departamento de Fisioterapia e Reabilitação

Avenida Roraima, s/n. Santa Maria, RS

masavo@terra.com.br 


\title{
RESUMO
}

Esta pesquisa teve o objetivo avaliar as condições de trabalho e os postos de trabalho dos operadores de caixa dos principais supermercados da cidade de Santa Maria (RS).Um total de 60 operadores de caixa de 9 supermercados foram incluídos no estudo. A coleta de dados foi realizada através de questionários, mensuração do posto de trabalho (antropometria e mobiliário), observações diretas e aplicação do check-list. Os resultados demonstraram condições de trabalho prejudiciais à saúde, como longas jornadas de trabalho e alta prevalência de desconfortos músculo-esqueléticos. A sintomatologia foi avaliada pelos trabalhadores como resultado de fatores relacionados ao trabalho, como movimentos biomecânicos de passagem e registro de mercadorias, posturas exigidas pelo posto de trabalho e mobiliário utilizado no posto de trabalho. As observações diretas analisaram as rotinas do trabalho e apontaram os movimentos realizados pelos operadores. A comparação entre medidas do mobiliário e antropometria demonstra incompatibilidade entre os componentes do posto de trabalho. A aplicação do check-list confirmou o alto risco de Distúrbio Osteomuscular Relacionado ao Trabalho e a necessidade de melhorias nas condições de trabalho desta categoria profissional.

Palavras-chave: Ergonomia, Caixas de Supermercados, Saúde Ocupacional.

\begin{abstract}
This research had the objective to appraised the supermarket cashiers work conditions and workstations of the main supermarkets of the city of Santa Maria (RS). A total of 60 supermarket cashiers from 9 supermarkets were included in this study. The collection of data was carried through questionnaires, workstations measures (anthropometry and furniture), in situ observations and a check list. The results had demonstrated harmful work conditions to the health, as long hours of working and high prevalence of musculoskeletal disorders. The complaints had been evaluated by the workers as resulted of factors related to the work, as biomechanic movements of cross and register of merchandises, positions demanded to work and furniture used in the work station. The comparison between measures of the furniture and anthropometry demonstrates incompatibility between the components of the workstation. The check list used confirmed the may contribute to a high risk for Repetitive Strain Injury and the necessity of improvements in the conditions of work of this professional category.
\end{abstract}

Key words: Ergonomics, Supermarket Cash Registers, Occupational health. 


\section{INTRODUÇÃO}

As inovações tecnológicas e organizacionais vêm causando importantes mudanças no trabalho, levando a uma nova relação homem-máquina e expondo o trabalhador a novos riscos à sua saúde. Esta realidade está sendo vivenciada pelos trabalhadores do setor de supermercados na substituição da caixa registradora pela leitura de código de barras no processo de registro de mercadorias pelos operadores de caixa.

Segundo Shinnar et al. (2004), embora o número de funcionários empregados como operadores de caixa tenham diminuído na última década nos Estados Unidos, o número de doenças ocupacionais tem aumentado nesta população. No Brasil, entre os trabalhadores do comércio e serviços, o setor de supermercados é o que apresenta maior incidência de Distúrbios osteomusculares relacionados ao trabalho (DORT) - um conjunto de afecções das estruturas do sistema osteomuscular, de origem ocupacional e decorrente de: uso repetitivo de grupos musculares; uso forçado de grupos musculares; e manutenção de posturas inadequadas que atingem principalmente os membros superiores, a região escapular e o pescoço (BRASIL, 1998).

Evidenciada inicialmente em digitadores, a DORT passou a ser também diagnosticada em profissões como caixas de supermercados e profissionais liberais. Esta abrangência fez com que estes distúrbios se tornassem os tipos de doenças do trabalho mais notificadas e que mais demandam aos serviços de saúde do trabalhador ao Instituto Nacional de Seguridade Social (INSS) na década de 90 (BRASIL, 1998). De acordo com Oliveira (2002), em virtude da dimensão do acometimento dos DORT, a Ergonomia adquiriu notoriedade no Brasil a partir da formulação pelo INSS da NR-17.

A utilização dos conceitos da Ergonomia no projeto de postos de trabalho auxilia na prevenção de acidentes e doenças ocupacionais, pois esta atua para adequar o trabalho ao homem, de modo a garantir o máximo de conforto, segurança e eficácia das ferramentas, máquinas e dispositivos utilizados pelo trabalhador, como explicitado por Wisner (1987).

As populações são compostas de indivíduos de diferentes tipos físicos, os quais apresentam diferenças nas proporções de cada segmento corporal (IIDA, 1997). Portanto, para que não haja lesões musculares, dores e fadiga, levando a lesões às vezes irreversíveis, os postos de trabalho devem estar adequados à população usuária. Em virtude desta realidade, é necessário buscar uma melhor adequação do posto de trabalho aos indivíduos que nele atuam, de acordo com os perfis populacionais e as áreas de atuação profissional. 


\section{MATERIAIS E MÉTODOS}

Trata-se de uma pesquisa descritiva, de caráter exploratório, com abordagem do tipo quantitativa e qualitativa.

Após aprovação pelo Comitê de Ética do Centro de Ciências da Saúde da Universidade Federal de Santa Maria, foram convidados a participar do estudo os supermercados da cidade que continham pelo menos três terminais de atendimento de caixa. A realização da investigação foi permitida por 9 estabelecimentos, nos quais solicitou-se a colaboração dos trabalhadores designados pela empresa como operadores de caixa.

A pesquisa foi realizada no período de março a julho de 2004, em horário regular de trabalho, mediante a assinatura de um termo de consentimento livre e esclarecido pelos 60 operadores de caixa de 9 supermercados de Santa Maria. A denominação fíctícia dos

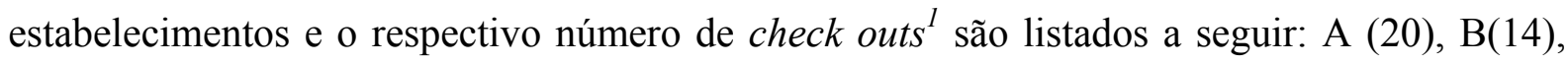
$\mathrm{C}(9), \mathrm{D}(6), \mathrm{E}(4), \mathrm{F}(4) \mathrm{G}(4), \mathrm{I}(4)$ e H (6). As lojas A, B e C são administradas pela mesma empresa, assim como D, E e F também são estabelecimentos de uma mesma rede.

Um questionário de sondagem contendo um diagrama proposto por Corlett e Manenica (IIDA, 1997) foi utilizado para caracterização sócio-demográfica e laboral da população estudada, os quais foram respondidos individualmente durante os intervalos proporcionados pela ausência de clientes.

As medidas antropométrica e do mobiliário foram coletadas através de protocolos adaptado de Iida, (1997) - e uma fita métrica em um local adaptado dos estabelecimentos, conservando a mesma cadeira utilizada no posto de trabalho. Todos os funcionários foram avaliados individualmente e simultaneamente pelas duas pesquisadoras, as quais, de forma a garantir a fidelidade dos dados, realizaram todas medidas deste estudo. O mobiliário foi mensurado de acordo com a quantidade de modelos utilizados em cada estabelecimento.

As observações das posturas e principais atividades exercidas durante a jornada de trabalho foram efetuadas mediante um protocolo baseado em Cruz et al. (2000), o qual lista as principais atividades desenvolvidas pelo caixa de supermercado. Foram analisados as principais atividades, posturas e movimentos realizados pelos indivíduos durante um atendimento, de duração mínima de cinco e máxima de quinze minutos.

\footnotetext{
${ }^{1}$ Conjunto de móveis e equipamentos usados para o registro e pagamento das mercadorias que estão saindo do mercado
} 
Em cada estabelecimento foi aplicado o Check-list para risco de DORT elaborado por Couto (1998). Este instrumento avalia a sobrecarga e os movimentos necessários para a realização de uma função específica no local em que esta é exercida.

\section{RESULTADOS E DISCUSSÃO}

\subsection{Caracterização e Epidemiologia}

A população caracterizou-se por idade média de 28 anos ( $\mathrm{DP}=7,35$ anos) e de sexo feminino (98,33\%), enquadrando-se no perfil epidemiológico de acometimento da DORT. A incidência deste conjunto de patologias é descrita por estes autores como uma das principais causas de incapacidade laboral em indivíduos jovens, em idade altamente produtiva e economicamente ativa. As mulheres são consideradas as mais atingidas em virtude da dupla jornada de trabalho de atividades domésticas (MAENO, 1999; NICOLETTI, 1999; RIBEIRO,1997).

O hábito de realizar exercícios físicos é um fator importante para a qualidade de vida do indivíduo, como abordado em estudo de Monteiro (1997), mas o hábito não está presente nesta população $(83,56 \%)$. As longas jornadas de trabalho e a quantidade de queixas ao final do dia de trabalho podem ser fatores que contribuam para a pouca atenção para hábitos com este.

O tempo de atuação como operador de caixa variou de menos de um ano $(38,9 \%)$ a 27 anos de serviço na função $(X=4 ; \mathrm{DP}=5,83)$. Diniz \& Ferreira (1998) verificaram que $80 \%$ dos trabalhadores que exercem esta função têm no máximo 2 anos de trabalho na mesma empresa e que 4 anos é o tempo máximo de permanência de um funcionário. Esses dados são compatíveis com os encontrados neste estudo, levando a concluir que a atividade de operador de check out, da forma como é executado atualmente, é desgastante e limitada, causando a exclusão precoce de uma faixa jovem da população ativa do mercado de trabalho.

Quanto ao nível de instrução, observou-se que escolaridade predominante é de nível médio $(72,88 \%)$ enquanto que uma minoria está cursando $(1,69 \%)$ ou terminou o nível superior (3,38\%). Apenas $6,78 \%$ dos funcionários não concluíram o ensino básico e são referentes aos trabalhadores com maior tempo de serviço. Estes números demonstram a exigência de uma qualificação cada vez maior do mercado de trabalho, fazendo com que a escolaridade de ensino médio seja a predominante nesta função. 
Dos trabalhadores estudados, 98,28\% possuem apenas um emprego. Isto pode ser justificado pela quantidade de horas de trabalhadas: 10h/dia $(1,69 \%)$; entre 9/10h/dia $(61,02 \%) ; 8 \mathrm{~h} /$ dia e entre 6-8h/dia $(3,39 \%)$. As longas jornadas são motivos de reclamações apontados pelas entidades do setor, como observado pela Federação do Comércio do Estado de Santa Catarina.

A maioria dos operadores realiza jornadas semanais de segunda-feira a sábado, folgando aos domingos. No entanto, em estabelecimentos que abrem aos domingos (A, B e C), as funcionárias trabalham sem folga semanal, recebendo um dia de descanso ao final de 13 dias de trabalho, o que impossibilita o descanso semanal recomendado (WISNER, 1987; MONTEIRO, 1997).

Nos estabelecimentos de maior porte $(\mathrm{A}, \mathrm{B}, \mathrm{C}, \mathrm{D}$ e $\mathrm{H})$ há intervalos pré-determinados para o afastamento do posto de trabalho, caracterizando pausas durante a jornada. Geralmente, a duração destes intervalos varia de 10 a 15 minutos (42,86\%). Isto é possível pelo revezamento proporcionado pelo maior número de funcionários, diferente dos estabelecimentos de menor porte em que há possibilidade de afastamento apenas quando o fluxo de clientes é baixo. No entanto, as pausas são importantes e devem ser de 5 a 10 minutos a cada hora de trabalho, a fim de evitar fadiga e dor (BRASIL, 2001).

Ao final da jornada da jornada de trabalho, $87,93 \%$ dos operadores de caixa apresentam algum desconforto músculo-esquelético, manifestado através de cansaço e/ou dor e/ou formigamento. Destes, $88,23 \%$ associaram esta sintomatologia a fatores relacionados ao trabalho, apontando causas distribuídas conforme a figura1.

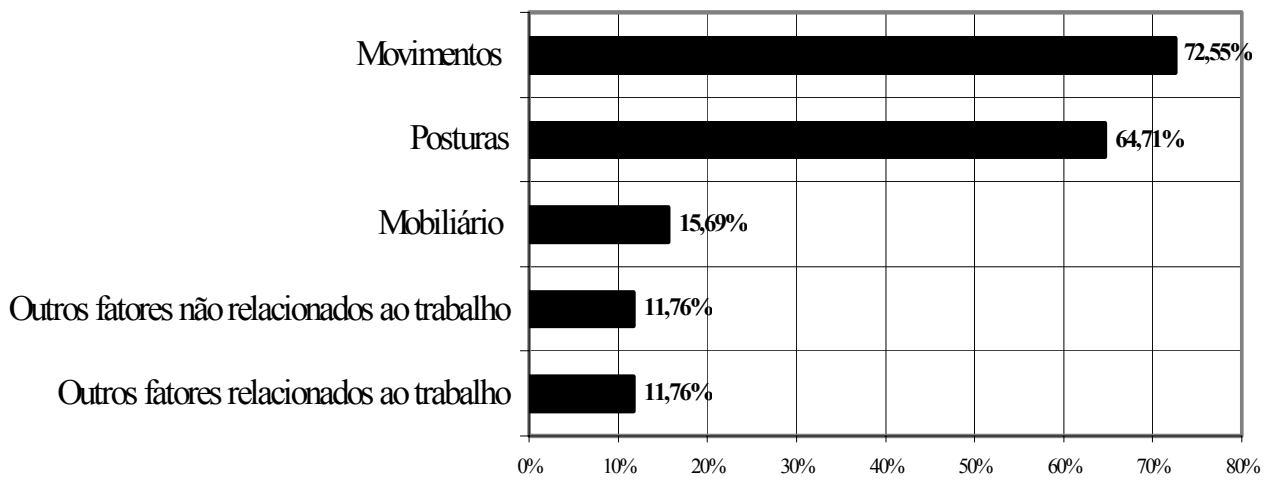

Figura 1: Causas relacionadas ao desconforto músculo-esquelético 
$\mathrm{Na}$ análise do diagrama de Corlett e Manenica, as queixas estão relacionadas as seguintes regiões: ombros $(74,5 \%)$, cintura escapular $(58,3 \%)$, braços $(49,01 \%)$, pernas (47,05\%), mãos e punhos (33,3\% cada), coxas $(31,37 \%)$, coluna torácica( $28,3 \%)$, antebraços $(25,49 \%)$, coluna lombar (25\%), coluna cervical $(23,3 \%)$, tornozelos e pés $(15,68 \%$ cada) e quadril (10\%). Nesta questão, cada indivíduo marcou, em média, 4,6 regiões das 11 indicadas.

Os locais mais acometidos pela DORT são regiões cervicais, escapulares e membros superiores, pois são as regiões mais sobrecarregadas durante o desempenho das tarefas laborais (WALSH et al., 2004; NICOLETTI 1999; RIBEIRO, 1997). Neste estudo, acreditase que a elevada incidência de queixas nos ombros deve estar associada aos movimentos repetitivos de passagem de mercadorias pelo check out, sobrecarga na elevação de produtos pesados, movimentos circulares para limpeza da superfície de trabalho e abdução e flexão constante do ombro, similares aos achados de Shinnar e. al. (2004).

O diagnóstico médico de doença relacionada ao trabalho já foi confirmado em $26 \%$ dos funcionários pesquisados, porém apenas $15,52 \%$ foram afastados do trabalho. Segundo o Estatuto da Previdência Social, é direito do trabalhador afastar-se do temporariamente em caso de doenças ocupacionais (BRASIL, 2001; MAENO, 1999; NICOLETTI, 1999). No entanto, o medo de perder o emprego foi justificado pelos funcionários deste estudo para o seu não-afastamento, sendo esta realidade um dos principais entraves para o diagnóstico e tratamento da DORT (NICOLETTI, 1999).

A aplicação estatística do teste de correlação linear de Pearson para um nível de significância de $\mathrm{p}<0,05$ demonstrou que não houve associação significativa entre prevalência de dor e fatores como idade, tempo de serviço ou prática de exercício físico. Assim, observase que as queixas de dor são uniformente distribuídas pela população, favorecendo a hipótese de que sejam relacionadas à atividade laboral.

\subsection{Análise antropométrica e do mobiliário}

A população estudada é destra (86,21\%), enquanto que $8,62 \%$ preferem o lado esquerdo e 5,17\% apresentam habilidades bilaterais. Os canhotos representam cerca de $10 \%$ da população, similar aos dados encontrados. Apesar de não se tratar de um valor desprezível, quase todos os produtos são projetados para destros, o pode dificultar o trabalho destas pessoas (IIDA, 1997; GRANDJEAN,1998). 
Os levantamentos antropométricos devem ser analisados em uma curva normal ou de Gauss, na qual é possível observar onde se encontram as medidas mais freqüentes de uma população. O valor desta medida menos dois desvios padrões (x-2s) e mais dois desvios padrões $(x+2 s)$ demonstram com confiança a faixa onde se situam, respectivamente, de 2,5 a 97,5\% da população estudada (IIDA, 1997; GRANDJEAN,1998).

A antropometria demonstra que há importantes diferenças entre as medidas do corpo, seja pelo sexo, idade e fatores étnicos. Exemplo disto são as medidas da população alemã descritas por Gradjean (1998), demonstrando que a estatura mínima das mulheres desta descendência é de $1,52 \mathrm{~cm}$ e máxima de $1,75 \mathrm{~cm}(\mathrm{X}=1,63 \mathrm{~cm})$. Já na região Sul do Brasil, esta medida encontra-se entre 1,49 e $1,68 \mathrm{~cm}(X=1,58 \mathrm{~cm})$ [9]. Nesta avaliação, os resultados encontrados situaram-se entre 1,52 e $1,74 \mathrm{~cm}(X=1,59 \mathrm{~cm} \quad \mathrm{DP}=7,43 \mathrm{~cm})$. Estes valores encontrados vão de encontro aos achados de Iida (1997).

De acordo com Iida (1997), projetos feitos no exterior nem sempre se adaptam aos brasileiros, e essas diferenças acentuam-se para o sexo feminino. Devido ao fato de que $98,33 \%$ dos indivíduos estudados serem do sexo feminino, os dados da literatura foram comparados com as medidas sugeridas para mulheres.

A alternância de postura nesta atividade deve ser considerada, por isso foram levantados dados na postura ortostática (Tabela I) e sentada (Tabela II). Segundo o Manual de Recomendações de Aplicação da NR-17, o mobiliário deve ser concebido com regulagens que permitam ao trabalhador adaptá-lo às suas características antropométricas. Deve principalmente permitir alternâncias de posturas (sentado e em pé), pois não existe nenhuma postura fixa que seja confortável [2].

\begin{tabular}{c|cccccc}
\hline Medida & $X$ & $S$ & $X-s$ & $X+s$ & $X-2 s$ & $X+2 s$ \\
\hline Alcance do braço & 65 & 3,99 & 61,1 & 69 & 57,1 & 73 \\
Estatura & 159,6 & 7,4 & 152,2 & 167,1 & 144,8 & 159,6 \\
Altura do cotovelo & 102,9 & 5,3 & 97,6 & 108,2 & 92,2 & 113,5 \\
Altura dos olhos & 149,9 & 8,3 & 141,5 & 158,2 & 133,1 & 166,6 \\
Altura do ombro & 131,9 & 5,97 & 125,9 & 137,8 & 119,9 & 143,8 \\
Tamanho da mão & 19,1 & 0,93 & 18,1 & 20 & 17,2 & 20,9 \\
\hline \multicolumn{7}{c|}{$X=$ média $S=$ desvio padrão *Medidas em centímetros }
\end{tabular}

Tabela I: Antropometria Ortostática. 


\begin{tabular}{c|cccccc}
\hline Medida & $X$ & $S$ & $X-s$ & $X+s$ & $X-2 s$ & $X+2 s$ \\
\hline Nádega-joelho & 46,2 & 3,9 & 42,3 & 50,1 & 38,3 & 54 \\
& & & & & & \\
Altura lombar & 86,4 & 4,81 & 81,6 & 91,2 & 76,8 & 96 \\
Altura do cotovelo & 88,9 & 4,37 & 84,5 & 93,3 & 80,2 & 97,7 \\
Altura dos olhos & 134,9 & 6,93 & 127,9 & 141,8 & 121 & 148,7 \\
Altura do ombro & 131,9 & 5,97 & 125,9 & 137,8 & 119,9 & 143,8 \\
Altura Poplítea & 43,4 & 3,62 & 39,7 & 46,9 & 36,1 & 50,6 \\
Largura do quadril & 32,2 & 5,14 & 27,1 & 37,38 & 21,9 & 42,5 \\
Altura da coxa & 75,1 & 3,92 & 71,7 & 79,6 & 67,8 & 83,5 \\
\hline
\end{tabular}

$X=$ média $S=$ desvio padrão *Medidas em centímetros

Tabela II: Antropometria em postura sentada.

Num assento adequado às dimensões antropométricas, a largura do assento deve ser proporcional à largura do quadril e nádegas; o comprimento deve ficar pelo menos a dois centímetros afastado da parte interna da perna (área poplítea); e a altura do assento deve proporcionar o apoio completo da coxa de modo a não comprimi-la excessivamente e permitindo o apoio total dos pés no solo.

Os projetos de assento devem considerar a relação entre a altura deste e da superfície de trabalho; a facilidade de sentar-se, levantar-se e movimentar-se livremente; a estabilidade proporcionada pelo assento e o estofamento do assento e de seu encosto (IIDA, 1997; GRANDJEAN,1998).

Alguns supermercados analisados não apresentavam boas condições de conservação das suas cadeiras, demonstrando falhas na graduação da regulagem de altura e ausência de rodízios nas cadeiras, dificultando os movimentos entre a superfície do check out e o emissor de ticket, conforme observado na tabela III.

A altura poplítea é a medida antropométrica que determina a altura do assento [8,9]. Os assentos cujas alturas sejam superiores ou inferiores à altura poplítea não permitem um assentamento firme das tuberosidades isquiáticas para transmissão do peso do corpo para o assento. A altura do assento deve ser regulável em movimentos contínuos e suaves e não por degraus. De acordo com as diferenças de medidas poplíteas da população adulta inglesa, a faixa de ajustes deve ser de 39 a $52 \mathrm{~cm}$ de altura. 


\begin{tabular}{|c|c|c|c|c|c|}
\hline Supermercado & Estofamento & Rodízios & $\begin{array}{c}\text { Apoio para } \\
\text { Pés }\end{array}$ & Apoio para Braços & Regulagem \\
\hline $\mathrm{A}$ & $\mathrm{S}$ & $\mathrm{S}$ & $\mathrm{S}$ & $\mathrm{N}$ & $\mathrm{S}$ \\
\hline $\mathrm{B}$ & $\mathrm{S}$ & $\mathrm{S}$ & $\mathrm{S}$ & $\mathrm{N}$ & ÀS VEZES \\
\hline $\mathrm{C}$ & $\mathrm{S}$ & $\mathrm{S}$ & ÀS VEZES & $\mathrm{N}$ & $\mathrm{S}$ \\
\hline $\mathrm{D}$ & $\mathrm{S}$ & $\mathrm{N}$ & $\mathrm{S}$ & $\mathrm{N}$ & $\mathrm{S}$ \\
\hline $\mathrm{E}$ & $\mathrm{S}$ & $\mathrm{N}$ & $\mathrm{S}$ & $\mathrm{N}$ & $\mathrm{S}$ \\
\hline $\mathrm{F}$ & $\mathrm{S}$ & $\mathrm{N}$ & $\mathrm{S}$ & $\mathrm{N}$ & $\mathrm{S}$ \\
\hline $\mathrm{G}$ & S & $\mathrm{S}$ & $\mathrm{N}$ & $\mathrm{N}$ & $\mathrm{N}$ \\
\hline $\mathrm{H}$ & S & $\mathrm{S}$ & $\mathrm{S}$ & $\mathrm{N}$ & S \\
\hline $\mathrm{I}$ & $\mathrm{S}$ & $\mathrm{S}$ & $\mathrm{S}$ & $\mathrm{N}$ & $\mathrm{S}$ \\
\hline SIM & 9 & 6 & 7 & 0 & 7 \\
\hline NÃO & 0 & 3 & 1 & 9 & 1 \\
\hline ÀS VEZES & 0 & 0 & 1 & 0 & 1 \\
\hline
\end{tabular}

Tabela III: Condições da cadeira.

Neste estudo observou-se que a altura poplítea média dos trabalhadores é de 43,36cm, com distribuição normal em $95 \%$ da população entre $36,1 \mathrm{~cm}(\mathrm{X}-2 \mathrm{~s})$ e $50,6(\mathrm{X}+2 \mathrm{~s})$, enquanto que as cadeiras apresentam regulagem entre 62 e $75 \mathrm{~cm}$. Devido à inadequação, não há possibilidade de apoio completo dos pés no chão. Para tentar amenizar esta condição, muitas cadeiras possuem um apoio circular localizado acima dos rodízios para o apoio parcial dos pés. No entanto, além deste aro não proporcionar apoio completo dos pés, o perímetro reduzido de sua circunferência faz com haja flexão de joelho além de $90^{\circ}$, prejudicando esta articulação. No entanto, este foi o único tipo encontrado, sendo considerado uma forma de apoio como demonstrado na Tabela III.

Quanto à superfície do assento, este deve ter de $40 \mathrm{a} 45 \mathrm{~cm}$ de largura para acomodar o quadril (GRANDJEAN, 1998). Neste estudo, a população possui medidas entre 21,9 e 42,5cm $(X=32,2)$, enquanto que os assentos medem de 38 a $44 \mathrm{~cm}$. Nota-se que, neste caso, o assento é adequado para a média da população, mas quanto mais os indivíduos afastam-se da média, pior a acomodação.

A medida de comprimento do assento deve possuir folga mínima de $2 \mathrm{~cm}$ a menos que a medida nádega-dobra interna do joelho. Por isso, as medidas entre 38 a $42 \mathrm{~cm}$ encontradas podem provocar compressão na fossa poplítea dos indivíduos com medida de $38,3 \mathrm{~cm}$, embora se considere adequado para a média $(X=46,2)$. 
A largura recomendável do encosto situa-se entre 32 e 36cm (GRANDJEAN, 1998). Neste estudo forma encontradas larguras entre 34 e $37 \mathrm{~cm}$ (X=34,56cm), considerada adequada.

O espaço livre recomendado entre o assento e o encosto deve ser de 15 a $20 \mathrm{~cm}$ para que este se situe entre as segunda e quinta vértebras lombares, permitindo liberdade de movimento ao tronco (IIDA, 1997; GRANDJEAN, 1998). Foram encontradas medidas de 13 a $23 \mathrm{~cm}$ $(\mathrm{X}=14,44 \mathrm{~cm}$ ). A altura de $23 \mathrm{~cm}$ (supermercado $\mathrm{B}$ ) pode ser considerada acima do esperado, posicionando o encosto ao nível da coluna torácica ao invés da lombar. O valor predominante de $13 \mathrm{~cm}$ classifica-se como adequado segundo a literatura, considerando-se a margem de variação estatística e as variações antropométricas.

A altura máxima do encosto encontrada na maioria dos locais é de $115 \mathrm{~cm}$ e a da altura lombar sentada de 76,8 a $96 \mathrm{~cm}(X=86,4 \mathrm{~cm})$. Esta medida está acima do esperado, pois limita os movimentos ao situar-se na coluna torácica.

\begin{tabular}{c|cccccccc}
\hline \multirow{2}{*}{ Supermercado } & Altura & $\begin{array}{c}\text { Altura } \\
\text { Máxima }\end{array}$ & $\begin{array}{c}\text { Minima } \\
\text { da Cadeira }\end{array}$ & Comprimento & $\begin{array}{c}\text { Altura do } \\
\text { Encosto }\end{array}$ & $\begin{array}{c}\text { Largura } \\
\text { Encosto }\end{array}$ & $\begin{array}{c}\text { Espaço } \\
\text { Livsento }\end{array}$ & Encosto \\
\hline A & 71,5 & 64,5 & 44 & 38,5 & 115 & 34 & 15 & 26 \\
$\mathrm{~B}$ & 70 & 62 & 38,5 & 38,5 & 105 & 36 & 23 & 46 \\
$\mathrm{C}$ & 70 & 65 & 40 & 40 & 115 & 34 & 13 & 28 \\
$\mathrm{D}$ & 73 & 67 & 43 & 38 & 115 & 34 & 13 & 28 \\
$\mathrm{E}$ & 73 & 67 & 43 & 38 & 115 & 34 & 13 & 28 \\
$\mathrm{~F}$ & 73 & 67 & 43 & 38 & 115 & 34 & 13 & 28 \\
$\mathrm{G}$ & 62 & 62 & 44 & 39 & 115 & 34 & 13 & 28 \\
$\mathrm{H}$ & 75 & 62 & 44 & 42 & 114 & 37 & 14 & 38 \\
$\mathrm{I}$ & 73 & 67 & 44 & 39 & 115 & 34 & 13 & 28 \\
\hline Mínimo & 62 & 62 & 38 & 38 & 105 & 34 & 13 & 26 \\
Média & 71,2 & 64,8 & 42,1 & 39 & 113,8 & 34,6 & 14,4 & 30,9 \\
Máximo & 75 & 67 & 44 & 42 & 115 & 37 & 23 & 46 \\
Desvio Padrão & 3,8 & 2,3 & 2 & 1,3 & 3,31 & 1,1 & 3,3 & 6,6 \\
\hline
\end{tabular}

*Medidas em centímetros

Tabela IV - Medidas da cadeira.

A superfície para o trabalho de média precisão, como este estudo classificou a operação de caixa, deve estar de 10 a $15 \mathrm{~cm}$ abaixo da altura do cotovelo[9]. Este levantamento demonstra que a maior parte dos operadores possui a altura do cotovelo quando sentados entre 80,2 a $97,7 \mathrm{~cm}(X=88,9 \mathrm{~cm})$.Assim, a superfície de trabalho de 85 e $96 \mathrm{~cm}$ 
$(\mathrm{X}=89,17 \mathrm{~cm})$ não está adaptada para a grande parte dos funcionários, pois não se situa abaixo mais sim ao nível do cotovelo.

Quanto maior o comprimento da superfície de trabalho, maior a dificuldade para o alcance e o esforço na passagem das mercadorias (IIDA, 1997; GRANDJEAN, 1998; OSHA, 2004). As medidas da largura frontal e lateral do check out devem ser proporcionais ao alcance do braço para a livre transferência de mercadorias. $\mathrm{O}$ alcance da maior parte dos operadores se dá entre 57,1 e $73 \mathrm{~cm}(X=65,05 \mathrm{~cm})$ o que faz com que a largura frontal (de 44 a $63 \mathrm{~cm}$ ) esteja apropriada para a média dos indivíduos. No entanto, a largura da porção lateral é apropriada apenas no local $\mathrm{G}(61 \mathrm{~cm})$, uma vez que permite movimentos apenas dentro da medida de alcance do braço.

É importante que haja espaço livre suficiente para acomodação das pernas, na parte frontal (profundidade) da bancada. Entre o assento e a mesa deve haver um espaço de pelo menos $20 \mathrm{~cm}$ para acomodar o membro inferior, permitindo movimentação das pernas [8,9]. A medida nádega-dobra interna do joelho encontrada variou entre 38,3 a $54 \mathrm{~cm}(X=46,19 \mathrm{~cm})$, apresentando-se adequada a toda população apenas no local I $(61 \mathrm{~cm})$. No estabelecimento E este espaço não existe, pois é ocupado por prateleiras com mercadorias.

Portanto, o projeto do check out deve prever altura suficiente para que o operador tenha espaço para as pernas na posição sentada, o que pode ser atendido pelas medidas antropométricas extremas (correspondente a $\mathrm{X}+2 \mathrm{~s}$ ) e prevendo apoio para os pés do operador mais baixo (correspondente a X-2s). A regulagem adequada de altura do assento também é imprescindível para permitir a manutenção em boa postura relativa à altura de trabalho (IIDA, 1997; GRANDJEAN, 1998;OSHA, 2004).

Quando comparado o espaço vertical à altura da coxa $(X=75,12)$, apenas os supermercados A $(125 \mathrm{~cm}), \mathrm{E}(77), \mathrm{H}(79 \mathrm{~cm})$ e I $(135 \mathrm{~cm})$ apresentam as medidas necessárias para a acomodação das pernas. Quanto ao espaço lateral, a sua presença é importante para a livre movimentação das pernas e da cadeira. Este parâmetro apresenta-se dentro dos valores necessários, pois está além do comprimento de $46,19 \mathrm{~cm}$ da medida nádega-dobra interna do joelho (Tabela V). 


\begin{tabular}{c|ccccccc}
\hline Supermercado & Altura & $\begin{array}{c}\text { Largura } \\
\text { Frontal }\end{array}$ & $\begin{array}{c}\text { Largura } \\
\text { Lateral }\end{array}$ & Comprimento & Profundidade & $\begin{array}{c}\text { Espaço } \\
\text { Vertical }\end{array}$ & $\begin{array}{c}\text { Espaço } \\
\text { Lateral }\end{array}$ \\
\hline $\mathrm{A}$ & 87,5 & 49 & 100 & 264 & 50 & 125 & 63 \\
$\mathrm{~B}$ & 92 & 55 & 105 & 198 & 29 & 74 & 77 \\
$\mathrm{C}$ & 89 & 52 & 103 & 224 & 47,5 & 75 & 72 \\
$\mathrm{D}$ & 86 & 45 & 95,5 & 193 & 32 & 68 & 78 \\
$\mathrm{E}$ & 85 & 44 & $* *$ & 152 & $* *$ & 77 & 77 \\
$\mathrm{~F}$ & 88 & 51 & 100 & 160 & 41 & 72 & 71 \\
$\mathrm{G}$ & 91 & 50 & 61 & 249 & 46 & 73 & 71 \\
$\mathrm{H}$ & 96 & 48 & 88 & 198 & 40 & 79 & 75 \\
$\mathrm{I}$ & 88 & 63 & 111 & 265 & 61 & 135 & $*$ \\
\hline Mínimo & 85 & 44 & 61 & 152 & 29 & 68 & 63 \\
Média & 89,2 & 50,8 & 95,4 & 211,4 & 43,3 & 86,4 & 73 \\
Máximo & 96 & 63 & 111 & 265 & 61 & 135 & 78 \\
Desvio Padrão & 3,4 & 5,7 & 15,46 & 41,95 & 10,2 & 25 & 4,9 \\
\hline "Medidas
\end{tabular}

*Medidas em centímetros **aracterística ausente

Tabela V : Medidas do check out.

Devido ao fato do supermercado I apresentar registro manual de mercadorias, a altura caixa da registradora foi considerada equivalente à altura do teclado para fins comparativos com os outros estabelecimentos.

Segundo Iida (1997), o teclado deve situar-se no mesmo nível do cotovelo. Considerando que a média de altura do cotovelo na posição ortostática é de $102,87 \mathrm{~cm}$ (Tabela 1) e sentado é de $88,05 \mathrm{~cm}$ (Tabela II), nos supermercados A e C o teclado é muito alto para o trabalho nas duas posturas; no B, é adequado para o trabalho em pé; já nos estabelecimentos F, G e I esta altura está adequada para a postura ortostática devido ao desvio padrão da altura do cotovelo em pé ser igual a $5,31 \mathrm{~cm}$. A altura do teclado no local E é adequada a postura sentada considerando-se o desvio padrão de 4,37. Os supermercados D e H não estão nos parâmetros adequados (Tabela VI).

Iida (1997) cita que a altura da tela deve estar adequada à linha dos olhos na posição horizontal. Comparando as medidas da altura dos olhos em pé (média de 149,86) com a altura da tela, foi considerada adequada a altura situada entre 141,50 a 158,21 cm devido ao desvio padrão de $8,35 \mathrm{~cm}$ da altura dos olhos. Então, apenas os locais $\mathrm{C}$ e E não se enquadram nesta variação.

Segundo Grandjean (1998), a altura dos olhos determina a linha de visão em relação a qualquer ponto desejado, estabelecendo a altura de terminais, painéis e visores. A altura dos olhos desta amostra na posição ortostática é de $149,86 \mathrm{~cm}$ e sentado de $133,91 \mathrm{~cm}$, sendo que o 
ideal da altura da tela para estes indivíduos deve ser similar a estes valores. Logo, foi considerado mais próximo do adequado as condições encontradas nos supermercados A $(149 \mathrm{~cm})$ e $\mathrm{D}(145)$ para o trabalho em pé e no C $(137 \mathrm{~cm})$ e E $(128 \mathrm{~cm})$ para o trabalho sentado.

A altura do ombro é um dado relevante para determinar as alturas do emissor de ticket, do leitor ótico e do teclado, seja na posição ortostática ou sentado. Neste levantamento, 50\% dos indivíduos apresentam a altura do ombro na posição ortostática no nível de $131,87 \mathrm{~cm}$ e sentada de 118, $06 \mathrm{~cm}$. Assim, a altura do emissor de ticket (87 a 117 cm) e do leitor ótico (105 e $116 \mathrm{~cm})$ não necessitam de elevações do ombro acima de $90^{\circ}$ em nenhuma posição adotada, pois estes se encontram abaixo da medida do ombro. O teclado encontra-se adequado para o trabalho em pé em todas as organizações, enquanto que para o trabalho sentado, também estão apropriados considerando o desvio padrão de 5,37 para a medida antropométrica.

\begin{tabular}{c|cccc}
\hline Supermercado & Altura do Teclado & Altura da Tela & Altura do Leitor & $\begin{array}{c}\text { Altura do Emissor } \\
\text { de Ticket }\end{array}$ \\
\hline A & 121 & 149 & 108,5 & 87 \\
B & 102 & 154 & 116 & 117 \\
C & 123 & 137 & 109 & 107 \\
D & 95 & 145 & 110 & 103 \\
E & 93 & 128 & 109 & 104 \\
F & 99 & 156 & 105 & 110 \\
G & 97 & 142 & 108 & 106 \\
H & 96 & 152 & 115 & 108 \\
I & 108 & $* *$ & $* *$ & 108 \\
\hline Mínimo & 93,00 & 128,00 & 105 & 87,00 \\
Média & 103,78 & 145,38 & 110,06 & 105,56 \\
Máximo & 123,00 & 156,00 & 116 & 117,00 \\
Desvio-Padrão & 11,23 & 9,47 & 3,01 & 8,05 \\
\hline
\end{tabular}

*Medidas em centímetros **não há

Tabela VI : Medidas do computador.

\subsection{Observações diretas e check list}

A associação das observações diretas com o checklist elaborado por Couto, (1995) permitiu a avaliação da atividade e da biomecânica ocupacional que esta requer. Os 9 supermercados avaliados apresentaram como resultado do checklist um total de 12 a 13 pontos, caracterizando um risco alto de DORT. Isto significa que a atividade exercida por 
estes profissionais apresenta vários problemas considerados prejudiciais, relacionados diretamente com:

1. Sobrecarga física e repetitividade: ausência de pausa definida e de rodízio de tarefas entre os trabalhadores, fazendo com que estes realizem o mesmo padrão de movimento durante toda a jornada.

2. Posturas adotadas (Biomecânica postural): o check-out não permite que o trabalho seja realizado com as articulações do membro superior em posição neutra, assim como as tarefas não são desenvolvidas sem elevação e abdução constante do membro superior.

3. Posto de trabalho: apenas a cadeira é passível de regulagem, embora muitos funcionários tenham demonstrado desconhecimento desta opção da cadeira e/ou não conheciam a relevância do ajuste para a sua postura. Em alguns casos, as más condições de conservação da cadeira não permitiam o ajuste.

4. Força aplicada com as mãos: ocorre pela necessidade de registro pelo leitor ótico de mercadorias com mais de $3 \mathrm{~kg}$ com pega dificultada.

A presença de um supermercado (I) que faz uso da caixa registradora permitiu a comparação deste sistema com o de leitura de códigos de barra, utilizado atualmente na maioria dos estabelecimentos. No sistema de registro manual, verificou-se que a maior freqüência de digitação aumenta a sobrecarga nos membros superiores e exige constantes rotações de tronco durante a passagem das mercadorias. Cruz et al. (2000) cita que no sistema convencional a coluna permanece mais intensamente em cifose, pois a máquina registradora fica distante e o deslocamento da cadeira é impossibilitado devido ao posicionamento da registradora.

Somente dois locais apresentavam esteira em todos os check outs (A e B) e um (C) a apresentava parcialmente.A ausência deste dispositivo implica em maior abdução do membro superior associado a inclinações de tronco para o alcance.

Quando o ritmo de trabalho é intenso, alguns operadores optam pela postura ortostática. Outros permanecem sentados, mas deixam de utilizar o encosto da cadeira. $\mathrm{O}$ posto de trabalho do caixa de supermercado é usualmente projetado para a posição sentada, com a possibilidade de alternância de postura, principalmente para manusear mercadorias pesadas peso - superior a 3 ou $4 \mathrm{~kg}$ (IIDA, 1997; GRANDJEAN, 1998). Algumas vezes, os 
operadores são auxiliados por empacotadores, agilizando o atendimento e diminuindo a força executada.

\section{CONSIDERAÇÕES FINAIS}

O índice de doenças relacionadas ao trabalho vem crescendo nas últimas décadas. Isto demonstra que a atividade laboral, quando realizada de forma inadequada ou em ambientes inapropriados, é capaz de gerar problemas físicos, psíquicos ou ambos. Estes problemas, à medida que se desenvolvem, transforma-se em doenças crônicas que muitas vezes podem evidenciar-se somente quando o trabalhador torna-se incapacitado.

Esta pesquisa aponta ainda questões significativas que constituem contribuições importantes à Ergonomia, pois comprova tanto a inadequação do posto de trabalho como deficiências na organização do trabalho dos operadores de caixa.

Os modelos de checkout encontrados nos principais estabelecimentos de Santa Maria não estão dimensionados para as variáveis de biótipos encontrados nesta amostra. Observa-se também que não há um padrão de mobiliário entre os supermercados estudados, mesmo entre aqueles submetidos à mesma administração. Desta forma, são demonstradas inadequações da altura da cadeira, da superfície de trabalho e da disposição dos componentes do check out, os quais muitas vezes não se adaptam nem a 50\% dos trabalhadores. Observou-se ainda que muitos check outs são antigos e foram adaptados para o trabalho com leitor ótico, realizando apenas a instalação do sistema sem alterações para as modificações de posturas e de necessidades do trabalhador. O mesmo ocorre com postos de trabalho projetados apenas para o trabalho em pé (ausência de espaço para as pernas) que passaram a disponibilizar assentos para a alternância de postura. Logo, improvisações constituem uma importante razão para as inadequações ergonômicas encontradas.

A população estudada é caracterizada em sua maioria por mulheres, jovens, com níveis médios de escolaridade, que exercem longas jornadas de trabalho diárias e semanais e que não realizam exercícios físicos regularmente. Embora mais de $70 \%$ exerçam esta função por um tempo máximo de três anos, esses trabalhadores apresentam-se com quantidade significativa de queixas nas principais regiões acometidas pela DORT, o que representa uma estatística importante a ser utilizada pelas equipes de saúde coletiva na prevenção de doenças ocupacionais. 
Entre os principais problemas encontrados na atividade de operadores de check out estão fatores como sobrecarga biomecânica, a repetitividade e os movimentos forçados de membros superior e tronco. Segundo Shinnar et al. (2004), um dos principais fatores que contribuem ao adoecimento dos operadores de caixa é o projeto do posto de trabalho, uma vez que este exige posturas que podem levar ao acometimento de patologias músculo-esqueléticas, e a pobre conscientização postural dos operadores para que estes possam reagir às agressões biomecânicas exigidas pelo posto de trabalho.

O design do posto de trabalho faz com que o operador adote posturas nem sempre adequadas à biomecânica corporal, como rotações e inclinações do tronco. Entretanto, o mobiliário não é fator exclusivo para a má postura e sobrecarga física, uma vez que foi observada a ausência de consciência corporal e de noções ergonômicas por parte dos trabalhadores. Isso pode ser exemplificado pelas posturas desleixadas durante o repouso e a ausência de parâmetros de avaliação do seu próprio posto de trabalho. Este fato torna-se relevante para enfatizar o papel imprescindível de programas organizacionais direcionados a conscientização e educação dos trabalhadores sobre segurança no trabalho e ergonomia, objetivando a promoção do bem-estar e saúde do funcionário.

No sistema de registro manual das mercadorias, verificaram-se freqüências maiores de digitação, elevando a sobrecarga nos membros superiores, além da exigência de rotações de tronco durante a passagem das mercadorias. No entanto, o número de mercadorias manuseadas num período de tempo aparenta ser menor. Como não foi possível mensurar estes indício, associado à baixa representatividade desta parcela da amostra em relação ao restante, não foi possível comparar este sistema com o de leitura de códigos de barra, utilizado atualmente na maioria dos estabelecimentos.

Além de ações organizacionais conjuntas entre empresa e trabalhadores, destacam-se como prioridades ergonômicas à presença de estofamento e de regulagem adequada para o assento, assim como do encosto e do apoio móvel para os pés. Também são imprescindíveis pausas pré-determinadas durante a jornada, alternância de posturas e esquemas previstos para o rodízio de tarefas. Deve-se enfatizar que muitas destas sugestões não impõem custos elevados para a empresa, e sim requerem apenas mudanças na política organizacional.

Para Shinnar et al. (2004), novos projetos de posto de trabalho de caixa de supermercado devem ser concebidos e testados, pois da forma como o sistema atual é concebido, não há como melhorar a biomecânica ocupacional e, conseqüentemente, o 
aparecimento de dores e queixas músculo-esqueléticas. Portanto, sugere-se que novos estudos possam testar melhorias no design deste posto de trabalho.

Conclui-se que a atividade dos operadores de caixas de supermercados, como evidenciado na pesquisa, é considerada de alto risco para o desenvolvimento de DORT, como evidenciado em estudos na Europa e Estados Unidos (SHINNAR et al, 2004; BARON et al, 1991; RYAN, 1989). Portanto, sugere-se uma intervenção ergonômica direcionada ao setor supermercadista, visando diminuir o risco de acometimento de patologias músculoesqueléticas nestes trabalhadores.

\section{REFERÊNCIAS}

BARON, S. et al. NIOSH health hazard evaluation report. HETA 88-344-2092. Shoprite Supermarkets, New Jersey, NY. 168-169:1991.

BRASIL, INSS. Distúrbios Osteomusculares Relacionados ao Trabalho. Brasília: MTE; 1998.

BRASIL, Ministério da Saúde. Departamento de Ações Programáticas e Estratégicas. Lesões por Esforços Repetitivos (LER) e Distúrbios Osteomusculares Relacionados ao Trabalho (DORT). Brasília; 2001; 103.

COUTO HA. Ergonomia aplicada ao trabalho: o manual técnico da máquina humana. 2v. Belo Horizonte: Ergo, 1995.

CRUZ et alli. Repercussões da introdução do sistema de leitura óptica no trabalho do operador de caixa de supermercado. Rev Ciências Humanas, Florianópolis: EDUFSC: 2000; 27:117-136. 
DINIZ C; FERREIRA $M$. Prevalência de sintomas músculo-esqueléticos em operadores de check out em mercados. Rev Bras Saúde Ocup 1998; 93-94:75-91

FECESC, Federação do Comércio do Estado de Santa Catarina. [2003 Out 12]. Disponível em URL:< http://www.fecesc.com.br

GRADJEAN, E. Manual de Ergonomia: adaptando o trabalho ao homem. Porto Alegre: Artes Médicas, 1998.

IIDA I. Ergonomia - Projeto e Produção. São Paulo: Edgard Blücher;1997.p.39-164.

MAENO M. et alli. Contribuição ao estudo dos Distúrbios Osteomusculares Relacionados ao Trabalho. São Paulo: INSS, 1999.

MONTEIRO JC. Lesões por Esforço Repetitivo: um estudo sobre a vivência do trabalhador portador de LER. Monografia (Pós-Graduação em Engenharia de Produção) - Universidade Federal de Santa Catarina, Florianópolis: 1997.p.1-69.

NICOLETTI S. L.E.R. São Paulo: Centro Brasileiro de Ortopedia Ocupacional; 1999:1: $1-16$.

OSHA, United States Department of Labor. Occupational Safety and Health Administration. Ergonomics for the prevention of musculoskeletal disorders: draft for retail grocerystores. Acessado em abril 2004. Disponível em URL: <http: //www.osha.gov/ergonomics/guidelines/grocerysolutions/grocsummary.pdf.

RIBEIRO H. Lesões por Esforços Repetitivos (LER): uma doença emblemática. Cad Saúde Pública 1997;13(2): 85-93.

RYAN, A.G. The prevalence of musculo-skeletal symptoms in supermarket workers. Ergonomics 32 (4), 359-371:1989.

SHINNAR A.; ALTINAR M, INDELICATO J, Survey of ergonomic features of supermarket cash registers. J Industrial Ergonomics 2004; 34: 535-541. 
WALSH IAP et alli.Capacidade para o trabalho em indivíduos com lesões músculoesqueléticas crônicas. Rev Saúde Pública 2004;38(2); 149 -56.

WISNER A. Por Dentro do Trabalho - Ergonomia: método e técnica. São Paulo: FTD; 1987.

Artigo Recebido em 09/10/2004 e aceito para publicação em 03/08/2005. 